\title{
Increasing food familiarity without the tears. A role for visual exposure?
}

Article

Accepted Version

Heath, P., Houston-Price, C. and Kennedy, O. B. (2011) Increasing food familiarity without the tears. A role for visual exposure? Appetite, 57 (3). pp. 832-838. ISSN 0195-6663 doi: https://doi.org/10.1016/j.appet.2011.05.315 Available at https://centaur.reading.ac.uk/21681/

It is advisable to refer to the publisher's version if you intend to cite from the work. See Guidance on citing.

To link to this article DOI: http://dx.doi.org/10.1016/j.appet.2011.05.315

Publisher: Elsevier

All outputs in CentAUR are protected by Intellectual Property Rights law, including copyright law. Copyright and IPR is retained by the creators or other copyright holders. Terms and conditions for use of this material are defined in the End User Agreement.

\section{www.reading.ac.uk/centaur}

\section{CentAUR}

Central Archive at the University of Reading

Reading's research outputs online 
Increasing food familiarity without the tears: A role for visual exposure?

\author{
Philippa Heath
}

Carmel Houston-Price

School of Psychology \& Clinical Language Sciences, University of Reading

Orla B. Kennedy

Hugh Sinclair Human Nutrition Unit, Department of Food \& Nutritional Sciences, University of Reading

Keywords: food preferences; fruit and vegetables; visual exposure; picture books; child

Please address correspondence to: Dr Carmel Houston-Price, School of Psychology \& Clinical Language Sciences, University of Reading, Earley Gate, Whiteknights, Reading, RG6 6AL. Tel: 0 (044) 118 3785378. Fax: 0 (044) 118 9316715. Email: c.houston-price@ reading.ac.uk 
Increasing food familiarity without the tears: A role for visual exposure?

\begin{abstract}
Research has established the success of taste exposure paradigms as a means of increasing children's acceptance, and liking, of previously unfamiliar or disliked foods. Yet, parents report that they tend to avoid the stress associated with repeatedly offering their children foods that are likely to be rejected. Given that successful taste exposure programmes often enhance children's familiarity with a food's appearance, as well as its taste, this article reviews the potential for exposure interventions that do not require repeated tastings to bring about positive attitude changes towards healthy foods. Recent evidence from studies that expose toddlers to picture books about fruit and vegetables suggest that familiarity with the origins and appearance of unfamiliar foods might increase children's willingness to accept these into their diets.
\end{abstract}




\section{Introduction}

The close relationship between an individual's eating habits in childhood, adolescence and adulthood (Ashcroft, Semmler, Carnell, van Jaarsveld \& Wardle, 2008; Devine, Connors, Bisogni \& Sobal, 1998; Kelder, Perry, Klepp \& Lytle, 1994; Nicklas, Webber \& Berenson, 1991; Nicklaus, Boggio, Chabanet \& Issanchou, 2004, 2005; Skinner, Carruth, Bounds, Ziegler \& Reidy, 2002) has led researchers and practitioners to explore techniques for increasing children's fruit and vegetable consumption from an early age. Current estimates suggest that preschool children consume only $70 \%$ of the recommended daily allowance of fruit and vegetables and that only one in five children achieve five portions a day (Cockroft, Durkin, Masding \& Cade, 2005; Gibson, Wardle \& Watts, 1998; Joint Health Surveys Unit, 2009; NHS Information Centre, 2009). Vegetable consumption is especially low in young children. In 1995, Buttriss reported that little more than half of preschoolers ate boiled vegetables such as peas and carrots; only $39 \%$ consumed leafy green vegetables and $24 \%$ raw vegetables. Little has changed since then. According to the recent National Diet and Nutrition Survey, preschoolers eat an average of $74 \mathrm{~g}$ of vegetables per day, less than one adult portion (Bates, Lennox \& Swan, 2010); in some regions of the UK, as many as $40 \%$ of pre-schoolers eat no vegetables at all (Cockroft et al., 2005).

In light of these statistics, this review explores the extent to which increasing young children's familiarity with vegetables might be employed as a means of boosting their vegetable consumption. We consider the impact of repeatedly exposing a child to a food's taste, an established means of enhancing acceptance of a food (Birch \& Marlin, 1982). However, we also explore the influence of food familiarity more generally, such as the benefits associated with hands-on experience of growing vegetables in school gardens (e.g. Morris \& Zidenberg-Cherr, 2002; Heim, Stang \& Ireland, 2009). The review discusses the impact of familiarising a child to a food's non-taste properties, with a particular focus on prior exposure to a food's visual appearance (Dovey, Staples, Gibson \& Halford, 2008; Tuorila, Meiselman, Bell, Cardello \& Johnson, 1994; Addessi, Galloway, Visalberghi \& Birch, 2005). Finally, 
we describe our recent and ongoing research into the impact of exposure to pictures of fruits and vegetables on toddlers' willingness to taste them (Heath, Houston-Price \& Kennedy, 2010; HoustonPrice, Burton, Hickinson, Inett, Moore, Salmon \& Shiba, 2009; Houston-Price, Butler \& Shiba, 2009; Houston-Price, Hill, Kennedy \& Owen, 2010) and we discuss the potential for an intervention based on visual exposure to facilitate efforts to increase children's vegetable consumption.

\section{Food neophobia and fruit and vegetable intake}

Attempts to increase children's fruit and vegetable intake face a number of barriers, such as children's innate dislike of bitter and sour tastes (Steiner, 1979), including the taste of bitter vegetables (Forestell \& Mennella, 2007) and their 'food neophobia', the tendency to reject unfamiliar foods without tasting them (Raudenbush \& Frank, 1999). Neophobia is not to be confused with 'food fussiness' or 'pickiness', which causes some children to reject a wide range of both familiar and unfamiliar foods; picky eaters tend to have a highly restricted diet, which may persist into adulthood (Galloway, Fiorito, Lee \& Birch, 2005 ; Dovey et al., 2008; Wardle \& Cooke, 2008). In contrast, neophobia is a specific distrust of unfamiliar foods (Raudenbush \& Frank, 1999) that typically peaks at 2 years of age and persists until 4 to 6 years (Cashdan, 1994; Cooke, Wardle \& Gibson, 2003). During the preschool years, almost all children display neophobic behaviour towards fruits and vegetables (Adessi et al., 2005; Birch \& Fisher, 1998; Birch, Gunder, Grimm-Thomas \& Laing, 1998; Cashdan, 1994, 1998; Cooke et al., 2003; Greenhalgh, Dowey, Horne, Lowe, Griffiths \& Whitaker, 2009). However, neophobia is a heritable trait, meaning that some children exhibit higher levels than others (Cooke, Haworth, \& Wardle, 2007; Knaapila, Tuorila, Silventoinen, Keskitalo, Kallela, Wessman et al., 2007). Cooke, Carnell \& Wardle (2006) estimate that highly neophobic preschoolers have a fruit and vegetable intake that is $35 \%$ lower than that of low neophobic children. 
Food neophobia is generally thought to be an adaptive mechanism that humans share with other animals to protect them from potentially harmful substances (Rozin, 1976); once a child is sufficiently mobile to be able to find and consume objects in his or her environment without parental guidance, neophobia works to prevent the ingestion of potentially toxic chemicals (Wright, 1991; Birch et al., 1998; Cashdan, 1998). Findings of neophobic behaviour in a variety of animal species, including nonhuman primates (Visalberghi \& Addessi, 2000) and rats (Rozin, 1976), support an evolutionary perspective on the origins of neophobia. Further support for this view comes from reports that neophobia is especially evident towards vegetables of the brassicaceae family (such as cabbages, broccoli \& brussel sprouts) and citrus fruits, plants whose non-fruit parts (such as leaves) contain poisonous compounds that are difficult to break down (Glander, 1982).

Neophobia can be overcome by consuming the unfamiliar food. The evolutionary account of this process is that the 'learned safety' of a food that is consumed without aversive consequence allows it to be accepted into the consumer's diet (Kalat \& Rozin, 1973). However, while a single 'safe' exposure to a food solution is sufficient for a rat to overcome its distrust of a new food, children's natural wariness of unfamiliar foods appears to abate more gradually, following repeated tastings (Birch, McPhee, Shoba, Pirok \& Steinberg, 1987; Birch \& Marlin, 1982). Some have therefore argued that knowledge of a food's safety is not the only factor driving the child's acceptance of previously rejected foods. Alternative accounts of the reversal of the neophobic response include 'flavour-flavour learning', whereby children come to accept a new food by associating it with already known and liked flavours (Havermans \& Jansen, 2007), and 'flavour-nutrient learning', whereby children accept a food after experiencing the positive consequences of absorbing its micronutrients (Havermans, 2010).

However, it is worth noting that neophobic behaviour is not restricted to the domain of unfamiliar foods. According to Bronson (1972), infants exhibit ambivalent reactions towards many new objects, their natural interest in engaging with their environment conflicting with their fear of the unfamiliar. 
Adults have also been shown to exhibit a negative response to new stimuli experienced through a variety of senses (including auditory, visual \& olfactory stimuli; Zajonc, 1968; Monahan, Murphy \& Zajonc, 2000; Perlman \& Oskamp, 1971). In the same way that repeated taste exposures to foods reduce children's neophobia, the adult aversion to novelty is also reported to diminish through repeated encounters. In fact, 'mere exposure', the sub- or supraliminal perception of a stimulus, is sufficient to engender a more positive attitude towards it (Zajonc, 1968). It is therefore possible that taste exposures enhance children's liking of a new food in a similar manner, simply by increasing the food's familiarity (Cooke, 2007).

\section{The impact of taste exposure on children's food uptake}

Researchers have therefore investigated whether offering children repeated tastes of an unfamiliar food might be employed as an intervention to enhance their acceptance, and even liking, of previously rejected foods. There is considerable support for the success of such tasting regimes (Birch et al., 1998; Birch \& Marlin, 1982; Birch et al., 1987; Busick, Brooks, Pernecky, Dawson \& Petzoldt, 2008; Forestell \& Menella, 2007; Lakkakula, Geaghan, Zanovec, Pierce \& Tuuri, 2010; Liem \& de Graff, 2004; Loewen \& Pliner, 1999; Pliner, 1982; Sullivan \& Birch, 1990; Wardle, Cooke, Gibson, Sapochnik, Sheiham \& Lawson, 2003; Wardle, Herrera, Cooke \& Gibson, 2003; Williams, Paul, Pizzo \& Riegel, 2008). For example, Birch and Marlin (1982) provided 2-year-old children with up to 20 opportunities to taste unfamiliar cheeses or fruits over a four-week period and found that 10 or more tastes of the food resulted in increased acceptance of it. Similarly, Sullivan and Birch (1990) demonstrated that 4- and 5-year-olds' preference for sweet, salted or plain tofu could be manipulated by asking children to taste one of the tofu products on 8 to 15 occasions. Such laboratory findings translate well to more naturalistic settings. Increases in preschoolers' and primary school-aged children's liking 
and consumption of vegetables have been shown to result from both parent-led and school-based taste exposure programmes (e.g. Lakkakula et al., 2010; Wardle et al., 2003a).

On the basis of such research, 10 to 15 taste exposures (or a daily tasting for a fortnight) have been proposed to be optimal for eliciting liking of a previously unfamiliar food in preschool-aged children. However, the majority of studies into the beneficial effects of taste exposure have involved children between the ages of 2 and 6 years, who are potentially highly neophobic. The very large numbers of taste exposures that research has found to be required to elicit liking of an unfamiliar food may, therefore, be associated with the onset of food neophobia in the second year; infants might be more accepting of new flavours and textures during the weaning period, when neophobia levels are comparatively low. Studies have produced mixed findings on this issue. Forestell and Mennella (2007) reported that eight exposures to the taste of green beans were sufficient to bring about an increase in consumption of this vegetable in 4- to 8-month-old infants. In the same age group, Birch et al. (1998) found a dramatic increase in intake of a never-before-tasted fruit (banana) and vegetable (peas) after only a single exposure to the target food. Nevertheless, a significant positive linear trend was observed in infants' consumption of the food with additional exposures, and by the tenth exposure, Birch et al. noted that consumption had more than doubled compared to baseline, suggesting that the optimal number of exposures may, in fact, be similar in infants and toddlers.

While the benefits of repeated taste exposure are evident, there can be difficulties in implementing the necessary taste opportunities in the home environment. Some parents exhibit food neophobia or eat only a restricted variety of foods themselves and, as a consequence, provide only a limited range of foods for their child to eat (Carruth \& Skinner, 2000; Wardle, Carnell \& Cooke, 2005). Even for parents who are well-intentioned about introducing their child to a varied and healthy diet, it can be difficult to persuade a reluctant toddler to try an unfamiliar or disliked food. In the case of unfamiliar foods, parents may mistakenly interpret a child's reaction to a novel food as an indication of the child's dislike of the 
food, and remove it from the child's diet as a result (Carruth \& Skinner, 2000; Carruth, Ziegler, Gordon \& Barr, 2004). Carruth and Skinner (2000) reported that parents are generally unwilling to coerce their child into tasting a food if they believe this is likely to result in 'bothersome behaviour'.

The evidence suggests that it may, in fact, not be advantageous to try too hard to persuade a child to taste a novel food. Tuorila and Mustonen (2010) found that children who only very reluctantly tasted a food were likely to develop even more negative attitudes towards the food; these authors recommend that parents treat children's reluctance to try new foods with sensitivity in order to avoid creating barriers to further familiarisation. Some children may even develop lasting taste aversions towards foods that they are forcefully or repeatedly required to eat, by associating the food with the negative emotions experienced during the eating episode (Batsell, Brown, Ansfield, \& Paschall, 2002; Fisher, Mitchell, Smiciklas-Wright \& Birch, 2002). In fact, research suggests that parents of preschool-aged children are typically prepared to offer a new food to their child on only three to five occasions before deciding that the child will not eat the food and giving up (Carruth \& Skinner, 2000; Carruth et al., 2004). During the weaning period, parents similarly stop offering their infant foods that they perceive to be disliked after only one to five attempts (Maier, Chabanet, Schaal, Leathwood \& Issanchou, 2007).

The difficulties parents face in achieving sufficient taste presentations to bring about liking of a new food clearly present a considerable obstacle to efforts to increase children's consumption of healthy foods through taste exposure. If, however, the crucial factor in overcoming a child's neophobia is the food's familiarity, as was discussed above, then it may be possible to increase acceptance of a food by enhancing its familiarity through some other means than taste exposure.

\section{The role of food familiarity in shaping children's food preferences}

Indirect support for the importance of food familiarity in shaping children's food choices comes from a variety of sources (see Aldridge, Dovey \& Halford, 2009, for a review). Correlational evidence 
linking children's consumption of fruit and vegetables with the availability and accessibility of these foods in the home (Blanchette \& Brug, 2005; Busick et al., 2008; Cullen, Baranowski \& Olvera, 2000; Cullen, Baranowski, Rittenberry, Cosart, Hebert \& de Moor, 2001; Wind, de Bourdeaudhuij, te Velde, Sandvik, Due, Klepp et al., 2006) and with parental intake of fruits and vegetables (Fisher et al., 2002; Skinner et al., 2002a; Wardle et al., 2005) suggests that regular encounters with fruit and vegetables may engender a willingness to consume them in the child. Further indirect evidence for a role for familiarity comes from studies demonstrating the positive impact of seeing others eating a food (Addessi et al., 2005; Birch, 1980; Cooke, Wardle, Gibson, Sapochnik, Sheiham \& Lawson, 2004; Dovey et al., 2008; Harper \& Sanders, 1975; Hendy, 2002; Hendy \& Raudenbush, 2000; Skinner, Carruth, Wendy \& Ziegler, 2002). Children's susceptibility to the power of food advertising is also compatible with the view that advertisements work by increasing the familiarity of a particular type or brand of food (Halford, Gillespie, Brown, Pontin \& Dovey, 2004; Lewis \& Hill, 1998; Story \& French, 2004). Interventions seeking to increase preschool- and school-aged children's fruit and vegetable consumption have tended to incorporate greater food familiarity as one component of a multi-pronged package. In Lowe and Horne's (2009) highly successful Food Dudes programme, for example, children watch a series of videos about a group of super hero peers who engage in combat against the unhealthy food-eating 'junk punks'. The Food Dudes are seen to enjoy eating fruit and vegetables and they encourage viewers to do the same through speech and songs imploring them to "keep the life force strong". During the 16-day school-based programme, children receive small non-food rewards for eating fruit and vegetables and teachers employ classroom wall charts and rewards to maintain consumption in the longer-term. Lowe, Horne, Tapper, Bowdery and Egerton (2004) reported that the Food Dudes programme produced a marked increase in children's consumption of fruit and vegetables, both at school and at home, with the greatest benefits seen in children with the lowest intake at baseline. While it is difficult to isolate the precise cause of children's increased consumption in such interventions, 
children's increased familiarity with the fruits and vegetables that are targeted by the programme may contribute to the effect.

Other work has explored whether enhancing a food's familiarity through 'hands-on' interaction can increase children's fruit and vegetable consumption. For example, Morris and Zidenberg-Cherr (2002) demonstrated that vegetable consumption could be improved by means of a school-based 'gardenenhanced nutrition curriculum'. Compared to children who did not take part in the special curriculum, young gardeners showed an increased knowledge of the vegetables that they had helped to grow, consumed more of these target vegetables at home and were more likely to ask their parents to buy them for home mealtimes. Importantly, these increases in liking of the target vegetables were still evident six months after the intervention had come to an end. Similarly, Heim et al.'s (2009) 12-week garden-based activity programme, in which children learned about, grew, prepared and tasted fruit and vegetables, led to significant increases in children's reported liking of the vegetables, greater willingness to try new fruits and vegetables and more requests for fruit and vegetables at home. The success of such studies has led the European Food Information Council (EUFIC, 2010) and the Department for the Environment, Food and Regional Affairs in the UK (DEFRA, 2010) to recommend that parents should involve their children in the growing and preparing of fruits and vegetables at home.

Concerns over children's fruit and vegetable consumption have also led to the development of educational programmes that allow children to explore and become familiar with healthy foods through enjoyable and practical activities, without the distress associated with tasting the foods. A programme that has grown in popularity with parents of preschool children in recent years is Lucy Thomas' Mange Tout (www.mangetoutkids.com), a nursery school-based course that introduces toddlers to three new fruits and vegetables each week through stories, music and activities. Children are encouraged to smell, touch and taste foods, without any pressure to eat them. For example, children inspect their teeth marks in an apple or tickle their tongues with broccoli. To date, there has been little scientific evaluation of the 
credibility of such programmes' claims to increase preschoolers' willingness to taste unfamiliar fruits and vegetables. However, sensory education programmes involving older school-aged children have reported that familiarisation with the sensory properties of foods can encourage children to be more agreeable about trying new foods. For example, Mustonen and Tuorila (2010) reported lower levels of food neophobia and greater willingness to taste novel foods in a group of 8- to 12-year-old children who had engaged in educational and practical activities to highlight different foods' tastes and odours (but see also Mustonen, Rantanen and Tuorila, 2009). Reverdy, Chesnel, Schlich, Köster and Lange (2009) also reported decreases in children's self-reported neophobia and increases in their willingness to taste unfamiliar foods immediately after children had taken part in a similar sensory education programme, although these positive effects were no longer apparent 10 months later.

Familiarity with the non-taste sensory properties of foods may, nevertheless, play a role in young children's food acceptance. Rozin and Schiller (1980) examined the process by which children in chillieating cultures come to accept and like chilli peppers, and concluded that liking develops through repeated experience of the heat sensation associated with eating chillis ('chilli-burn'). Familiarity with a food's smell may also impact on liking. For example, Macfarlane (1975) demonstrated that repeated exposure to the odour of the mother's breast milk during the first week of life plays an important role in the development of an infant's preference for the mother's milk. Exposure to different textures of foods has also been found to shape children's preferences. Blossfeld, Collins, Kiely and Delahunty (2007) found that 12-month-olds' liking of and willingness to consume chopped carrots was positively related to the frequency with which the child had been exposed to chopped foods during the weaning period. One aspect of food familiarity that has received relatively little attention, however, is children's familiarity with the visual appearance of a food. The next section reviews the evidence regarding the impact of experience of foods in the visual domain on food liking and uptake. 


\section{Familiarity with the visual appearance of a food}

When one considers that a child's neophobic rejection of an unfamiliar food typically occurs before the food has been tasted, primarily on the basis of a visual judgement about the food's desirability, there are good grounds for thinking that a food's appearance might play an important role in a child's decision about whether or not to consume it. Preschoolers and older children will taste foods only if they match the child's ideas about what is acceptable in the visual domain (Dovey et al., 2008), and attitudes towards new foods are highly influenced by previous positive and negative experiences with similarlooking foods (Tuorila et al., 1994). Furthermore, Addessi et al. (2005) found that children were more likely to imitate peer models in consuming artificially-coloured semolina when the observed and offered foods matched in colour. Familiarity with the appearance of a food is therefore highly likely to impact on its acceptability to the child.

While there have been few direct investigations of the influence of visual familiarity, interventions seeking to increase children's consumption of fruit and vegetables have, almost without exception, enhanced the visual familiarity of the target food in parallel with the familiarity of its taste, texture, or origins. For example, in studies that offer children repeated tastes of a new food, the food is both seen and tasted on each occasion that it is provided. Where children have been involved in growing vegetables in school gardens and preparing them for consumption, children will have become familiar with the appearance of the foods they have grown. Children's awareness of the availability of foods comes about through their visual experience of foods in the home, and the impact of advertisements, videos and parent / peer models are all absorbed through visual observation. It is therefore feasible that the mechanism that underpins the effectiveness of each of these interventions is their impact on children's visual familiarity with the target foods.

To explore this possibility, Birch et al. (1987) directly compared the effects of visual exposure and taste exposure on children's ratings of six unfamiliar fruits; the results led Birch et al. to conclude that 
visual exposure alone was insufficient to change children's liking of a food. In this study, fruits were presented 5, 10 or 15 times over a 30-day period; children were asked to taste three of the fruits and to only look at the other three. Following the exposure period, children were presented with pairs of fruits and were asked to "choose the one you like the best" both before the pair of foods was tasted ('look judgements') and afterwards ('taste judgements'). Children's look judgements were positively correlated with the number of exposures children received to the fruits, whether these were visual or taste exposures, while taste judgements were related only to the number of taste exposures the child had received. These findings suggest that children's liking of the taste of a new food is not affected by their familiarity with its visual appearance. However, surprisingly little attention has been paid to Birch et al.'s finding that visual exposure enhanced children's ratings of how much they liked the food before they were asked to taste it. For example, it remains unknown whether the positive attitude that was elicited by looking at the fruit might encourage children to approach, touch or even taste the food if the opportunity arose. Given that willingness to taste a food is associated with positive hedonic experiences and with greater acceptance of the food when it is tasted (Raudenbush \& Frank, 1999; Tuorila \& Mustonen, 2010), the potential for visual exposure to enhance a child's willingness to taste foods deserves exploration.

Recent work by our group at the University of Reading has therefore investigated the potential for exposure to the appearance of a food to impact on children's interest in and willingness to taste the food at around 24 months of age, when neophobia is approaching its peak. Houston-Price et al. (2009a) provided parents of 17- to 27-month-old toddlers with books containing pictures and information about fruits and vegetables, which they were asked to read with their children on a daily basis for either one, two or three weeks. The impact of the intervention on children's interest in the target foods was measured in terms of children's visual preferences: the amount of time they spent looking at pictures of exposed fruits or vegetables rather than pictures of previously non-exposed foods. Across a series of 
three studies, this type of picture-book intervention caused children to spend significantly longer attending to the fruits and vegetables they had seen in their books. This effect was strongest when parents were asked to read the book daily for a fortnight, when an average of 9 readings were actually recorded by parents. This finding is noteworthy as it suggests that the number of visual exposures required to elicit the optimal effect is comparable to the recommended number of taste exposures (Birch \& Marlin, 1982; Birch et al., 1987; Sullivan \& Birch, 1990; Wardle et al, 2003b; Lakkakula et al., 2010). Children's preference for picture-book exposed foods was evident both when the pictures presented at test were identical to the pictures children had seen in their books and when new pictures of exposed foods were shown, leading Houston-Price et al. to suggest that children's visual preferences were driven not by the perceptual familiarity of the exposed pictures but by increases in children's interest in the exposed foods themselves.

A second study by Houston-Price et al. (2009b) explored whether picture books influence children's willingness to taste new foods in the same way that they enhance children's interest in looking at the foods. Parents of toddlers aged 21 to 24 months were asked to read a picture book about two familiar foods (such as sweetcorn \& strawberries) and two unfamiliar foods (such as radishes and lychees) with their child every day for a fortnight. Children then took part in a 'taste test', in which they were offered a plate of four vegetables, followed by a plate of four fruits. Each child had seen two of the four items on each plate in their picture books. Children were encouraged to taste the foods presented and we recorded the order in which foods were touched or tasted. Children tasted significantly more familiar foods than unfamiliar foods, in a classic demonstration of neophobic behaviour. However, the order in which children approached the unfamiliar foods on each plate was affected by the books they had been reading; children touched the vegetable they had seen in their book before the non-exposed vegetable and they tasted the fruit they had seen in their book before the non-exposed fruit. This study therefore provides preliminary evidence that an exposure programme that does not involve food tasting can 
influence the foods that children are prepared to approach. However, an additional, more unexpected, finding of the study was that the vegetables that were already familiar to children were less likely to be tasted in our taste test if children had seen them in their picture books than if they had not.

The pattern of findings reported by Houston-Price et al. (2009b) suggests that visual exposure to foods has the potential to elicit both positive and negative effects on a child's willingness to taste a food, depending on the child's prior familiarity with the food. Repeated taste exposures have similarly been reported to lead to a decreased desire for the food in some circumstances. For example, when Liem and Zandstra (2009) asked children to consume the same snack food every day for three weeks, children's desire for the snack declined due to the monotony of eating the same food every day. Even after a single lunch session, preschoolers and adults have been reported to display 'sensory specific satiety', a decrease in the reported pleasantness of the recently consumed flavour or texture (Birch \& Deysher, 1986; Rolls, 1986). Sensory specific satiety is thought to play an important role in appetite regulation and to promote the selection of dietary variety (Rolls \& Hetherington, 1989; Rolls, Rolls, Rowe \& Sweeney, 1981). However, children can also become satiated with variety. Loewen and Pliner (1999) found that 7- to 9-year-olds who were exposed to a large number of unfamiliar foods in a short space of time were less willing to try further unfamiliar foods, which they explained in terms of 'quota overload'. Other work suggests that the success of a repetitious exposure intervention may depend on the food's status as liked or disliked prior to the exposure regime. For example, Pliner, Polivy, Herman and Zakalusny (1980) found that 'too much of a good thing' led to dislike of a previously liked food. The negative effect that Houston-Price et al. (2009b) reported for familiar vegetables might have a similar cause. While no measure was taken of the extent to which children liked the familiar foods in that study, it is possible that children's disinterest in tasting the familiar vegetables was a result of being repeatedly exposed to pictures of foods that they already enjoyed. 
Heath et al. (2010) therefore set out to establish whether children's prior familiarity with, or liking of, a fruit or vegetable, as reported by parents, moderates the extent to which picture-book exposure enhances children's interest in the foods depicted. In this study, interest was indexed by children's visual attention towards exposed versus non-exposed foods, as in Houston-Price et al. (2009a). Sixty toddlers aged between 20 and 24 months looked at picture books about a fruit or a vegetable every day for two weeks with their parents, after the food's status as liked, disliked or unfamiliar had been determined by parental report. Children then took part in a visual preference test, in which pictures of exposed and non-exposed foods of the same status were paired. No negative effects were observed to result from picture-book exposure for foods of any status; rather, children showed positive preferences for exposed foods across the five food groups (see Figure 1). However, it is interesting to note that stronger effects were seen for previously disliked and unfamiliar foods, relative to foods that were already liked. These findings suggest that visual exposure carries the greatest benefits where there is most scope to increase children's familiarity with or liking of a food and therefore support the potential for a picture-book intervention to be pursued as a means of enhancing the variety of fruits and vegetables that young children might be willing to taste. Moreover, given that similar effect sizes were observed in this study for children with both high and low levels of food neophobia, as measured by the Child Food Neophobia Scale (Pliner, 1994), the results suggest that a visual exposure intervention might be employed successfully with children who usually show high levels of resistance to new foods and for whom taste exposure regimes could be especially problematic.

Current work by our group is exploring whether the effects of picture-book exposure that have been seen in children's looking and eating behaviour in the laboratory environment translate into the home eating environment. Specifically, we are investigating whether parents' attempts to introduce their toddlers to new or disliked fruits and vegetables are facilitated by a prior period of picture-book exposure. This work will clarify whether visual exposure is beneficial for children with both high and 
low levels of food neophobia. In addition, we hope to shed light on the means by which visual exposure has its effects, by identifying any changes that occur in parents' and/or children's food-related behaviours and attitudes as a direct result of reading the books. Preliminary results suggest that parents are noticing immediate changes in children's behaviour towards visually-exposed foods, including an increased interest in talking about the food and a greater likelihood of consuming it (Houston-Price et al., 2010). Interestingly, parents are also reporting increases in their own consumption of target fruits during the book-reading period. The positive effects that picture-book exposure appears to have on children's food-related behaviours may therefore be mediated by the impact of observing parents eating the target food more often (Fisher et al., 2002).

There is clearly considerable scope for further work to explore and corroborate these preliminary, but exciting, results, and whether a picture-book intervention could prove successful in facilitating children's uptake of fruit and vegetables in the longer term remains to be seen. Researchers might also find it fruitful to investigate the benefits associated with alternative means of manipulating the visual familiarity of healthy foods. Reading a picture book about a food is, after all, not the only way to increase a child's familiarity with it. For example, further research might examine whether the influence of familiarity is diminished if the exposure is incidental, rather than socially mediated, as would be the case if pictures of foods were merely displayed on the walls of the child's bedroom. Further research is similarly needed into the relative effectiveness of exposure to pictures of foods versus real foods in the supermarket or home environment. Interaction with real foods affords the opportunity to learn about their smell and texture, as well as their appearance; familiarity with several of a food's properties might have an even greater effect on the child's willingness to taste it. It is our opinion that this line of research is worth pursuing. Parents who are participating in our current research are highly enthusiastic about the changes they are seeing in their children's attitudes, not only towards the target foods, but also towards other new foods. By learning that one previously disliked or unfamiliar food is good to eat, 
children appear to become more willing to 'take a chance' on other unfamiliar foods. If this is the case, then spending two weeks reading a book about a single food could have far-reaching consequences for the variety of healthy foods in a child's diet. 


\section{References}

Addessi, E., Galloway, A.T., Visalberghi, E. \& Birch, L. (2005). Specific social influences on the acceptance of novel foods in 2-5-year-old children. Appetite, 45, 264-271.

Aldridge, V., Dovey, T.M. \& Halford, J.C.G. (2009). The role of familiarity in dietary development. Developmental Review, 29, 32-44.

Ashcroft, J., Semmler, C., Carnell, S., van Jaarsveld, C.H. \& Wardle, J. (2008). Continuity and stability of eating behaviour traits in children. European Journal of Clinical Nutrition, 62, 985-990.

Bates, B., Lennox, A. \& Swan, G. (2010). National diet and nutrition survey: Headline results from year 1 of the rolling programme (2008/2009). Food Standards Agency \& Department of Health, http://www.food.gov.uk/science/dietarysurveys/ndnsdocuments/ndns0809year1

Batsell, R.W., Brown, A.S., Ansfield, M.E. \& Paschall, G.Y. (2002). You will eat all of that! A retrospective analysis of forced consumption episodes. Appetite, 38, 211-219.

Birch, L.L. (1980). Effects of peer models' food choices and eating behaviors on preschoolers' food preferences. Child Development, 51, 489-496.

Birch, L.L. \& Deysher, M. (1986). Caloric compensation and sensory specific satiety: Evidence for self regulation of food intake by young children. Appetite, 7, 323-331.

Birch, L.L. \& Fisher, J.O. (1998). Development of eating behaviors among children and adolescents. Pediatrics, 101, 539-549.

Birch, L.L., Gunder, L., Grimm-Thomas, K. \& Laing, D.G. (1998). Infants' consumption of a new food enhances acceptance of similar foods. Appetite, 30, 283-295.

Birch, L.L. \& Marlin, D.W. (1982). I don’t like it; I never tried it: Effects of exposure on two-year-old children's food preferences. Appetite: Journal for Intake Research, 3, 353-360.

Birch, L.L., McPhee, L., Shoba, B.C., Pirok, E. \& Steinberg, L. (1987). What kind of exposure reduces children's food neophobia? Looking vs. tasting. Appetite, 9, 171-178. 
Blanchette, L. \& Brug, J. (2005). Determinants of fruit and vegetable consumption among 6-12-yearold children and effective interventions to increase consumption. Journal of Human Nutrition and Dietetics, 18, 431-443.

Blossfeld, I., Collins, A., Kiely, M. \& Delahunty, C. (2007). Texture preferences of 12-month-old infants and the role of early experiences. Food Quality \& Preference, 18, 396-404.

Bronson, G.W. (1972). Infants' reactions to unfamiliar persons and novel objects. Monographs of the Society for Research in Child Development, Serial no. 148, vol. 37, no. 3.

Busick, D.B., Brooks, J., Pernecky, S., Dawson, R. \& Petzoldt, J. (2008). Parent food purchases as a measure of exposure and preschool-aged children's willingness to identify and taste fruit and vegetables. Appetite, 51, 468-473.

Buttriss, J. (1995). Survey of preschool eating habits. Nutrition \& Food Science, 4, 24-27.

Carruth, B.R. \& Skinner, J.D. (2000). Revisiting the picky eater phenomenon: Neophobic behaviors of young children. Journal of the American College of Nutrition, 19, 6, 771-780.

Carruth B.R., Ziegler P.J., Gordon A. \& Barr S.I. (2004). Prevalence of picky eaters among infants and toddlers and their caregivers' decisions about offering a new food. Journal of the American Dietetic Association, 104, 57-64.

Cashdan, E. (1994). A sensitive period for learning about food. Human Nature, 5, 279-291.

Cashdan, E. (1998). Adaptiveness of food learning and food aversions in children. Social Science Information, 37, 613-632.

Cockroft, J., Durkin, M., Masding, C. \& Cade, J. (2005). Fruit and vegetable intakes in a sample of preschool children participating in the 'Five for All' project in Bradford. Public Health Nutrition, 8, 861-869.

Cooke, L. (2007). The importance of exposure for healthy eating in childhood: A review. Journal of Human Nutrition \& Dietetics, 20, 294-301. 
Cooke, L., Carnell, S. \& Wardle, J. (2006) Food neophobia and mealtime food consumption in 4-5 year old children. International Journal of Behavioral Nutrition and Physical Activity, 3, 14.

Cooke, L., Haworth, C., \& Wardle, J. (2007). Genetic and environmental influences on children's food neophobia. American Journal of Clinical Nutrition, 86, 428-433.

Cooke, L., Wardle, J. \& Gibson, E.L. (2003). Relationship between parental report of food neophobia and everyday food consumption in 2-6-year-old children. Appetite, 41, 205-206.

Cooke, L., Wardle, J., Gibson, E., Sapochnik, M., Sheiham, A. \& Lawson, M. (2004). Demographic, familial and trait predictors of fruit and vegetable consumption by pre-school children. Public Health Nutrition, 7, 295-302.

Cullen, K.W., Baranowski, T.R. \& Olvera, N. (2000). Social-environmental influences on children's diets: Results from focus groups with African-, Euro- and Mexican-American children and their parents. Health Education Research, 15, 581-590.

Cullen, V., Baranowski, T., Rittenberry, L., Cosart, C., Hebert, D. \& de Moor, C. (2001). Child-reported family and peer influences on fruit, juice and vegetable consumption: Reliability and validity of measures. Health Education Research, 16, 187-200.

DEFRA (2010). Report of the fruit and vegetables task force, August 2010.

http://www.defra.gov.uk/foodfarm/food/policy/partnership/fvtf/index.htm

Devine, C., Connors, M., Bisogni, C. \& Sobal, J. (1998). Life-course influences on fruit and vegetable trajectories: Qualitative analysis of food choices. Journal of Nutrition Education \& Behavior, 30, 361-370.

Dovey, T.M., Staples, P.A., Gibson, E.L. \& Halford, J. (2008). Food neophobia and 'picky/fussy' eating in children: A review. Appetite, 50, 181-193. 
EUFIC (2010). Encouraging young children to eat different vegetables.

http://www.eufic.orgarticle/en/page/FTARCHIVE/artid/Encouraging-young-children-eat-differentvegetables/

Fisher, J.O., Mitchell, D.C., Smiciklas-Wright, H. \& Birch, L.L. (2002). Parental influences on young girls' fruit and vegetable, micronutrient, and fat intakes. Journal of the American Dietetic Association, 102, 58-64.

Forestell, C.A. \& Mennella, J.A. (2007). Early determinants of fruit and vegetable acceptance. Pediatrics, 120, 1247-1254.

Galloway, A.T., Fiorito, L.M., Lee, Y. \& Birch, L.L. (2005). Parental pressure, dietary patterns and weight status among girls who are "picky eaters". Journal of the American Dietetic Association, $105,541-548$.

Gibson, E.L., Wardle, J. \& Watts, C. (1998). Fruit and vegetable consumption, nutritional knowledge and beliefs in mothers and children. Appetite, 31, 205-228.

Glander, K.E. (1982). The impact of plant secondary compounds on primate feeding behavior. American Journal of Physical Anthropology, 25, 1-18.

Greenhalgh, J., Dowey, A., Horne, P.J., Lowe, C.F., Griffiths, J.H. \& Whitaker, C.J. (2009). Positiveand negative peer modelling effects on young children's consumption of novel blue foods. Appetite, $52,646-653$.

Halford J.C., Gillespie, J., Brown, V., Pontin, E.E. \& Dovey, T. (2004). Effect of television advertisements for foods on food consumption in children. Appetite, 42, 221-225.

Harper, L. \& Sanders, K. (1975). The effects of adults' eating on young children's acceptance of unfamiliar foods. Journal of Experimental Child Psychology, 20, 206-214. 
Havermans, R.C. (2010). Increasing children's liking and intake of vegetables through experiential learning. In R. Watson \& V. Preedy (Eds.), Bioactive foods in promoting health: Fruits and vegetables, pp. 273-283. London: Elsevier.

Havermans, R. \& Jansen, A. (2007). Increasing children's liking of the taste of vegetables through flavour-flavour learning. Appetite, 48, 259-262.

Heath, P.M., Houston-Price, C. \& Kennedy, O.B. (2010). Can visual exposure impact on children's visual preferences for fruit and vegetables? Proceedings of the Nutrition Society, 69 (OCE6), E422.

Heim, S., Stang, J. \& Ireland, M. (2009). A garden pilot project enhances fruit and vegetable consumption among children. Journal of the American Dietetic Association, 109, 1220-1226.

Hendy, H.M. (2002). Effectiveness of trained peer models to encourage food acceptance in preschool children. Appetite, 39, 217-225.

Hendy, H.M. \& Raudenbush, B. (2000). Effectiveness of teacher modeling to encourage food acceptance in preschool children. Appetite, 34, 61-76.

Houston-Price, C., Burton, E., Hickinson, R., Inett, J., Moore, E., Salmon, K. \& Shiba, P. (2009a).

Visual exposure elicits positive visual preferences in toddlers. Journal of Experimental Child Psychology, 104, 89-104.

Houston-Price, C., Butler, L. \& Shiba, P. (2009b). Visual exposure impacts on toddlers' willingness to taste fruit and vegetables. Appetite, 53, 450-453.

Houston-Price, C., Hill, C., Kennedy, P.B. \& Owen, L.H. (2010, Sept). The impact of picture-book exposure on parents' food choices for their children. Paper presented at the British Psychological Society Developmental Psychology Section Annual Conference. Goldsmiths, University of London. Joint Health Surveys Unit (2009). Health survey for England 2008 trend tables. The NHS Information Centre, http://www.ic.nhs.uk/pubs/hse08trends 
Kalat, J. \& Rozin, P. (1973). "Learned safety" as a mechanism in long-delay taste-aversion learning in rats. Journal of Comparative \& Physiological Psychology, 83, 198-207.

Kelder, S., Perry, C., Klepp, K. \& Lytle, L. (1994). Longitudinal tracking of adolescent smoking, physical activity, and food choice behaviors. American Journal of Public Health, 84, 1121-1126.

Knaapila, A., Tuorila, H., Silventoinen, K., Keskitalo, K., Kallela, M., Wessman, M., Peltonen, L., Cherkas, L.F., Spector, T.D. \& Perola, M. (2007). Food neophobia shows heritable variation in humans. Physiology \& Behavior, 91, 573-578.

Lakkakula, A., Geaghan, J., Zanovec, M., Pierce, S. \& Tuuri, G. (2010). Repeated taste exposure increases liking for vegetables by low-income elementary school children. Appetite, 55, 226-231.

Lewis, M. \& Hill, A. (1998). Food advertising on British children's television: Content analysis and experimental study with nine year olds. International Journal of Obesity, 22, 206-214.

Liem, D.G. \& de Graaf, C. (2004). Sweet and sour preferences in young children and adults: Role of repeated exposure. Physiological Behaviour, 83, 421-429.

Liem, D.G. \& Zandstra, L.H. (2009). Children's liking and wanting of snack products: Influence of shape and flavour. International Journal of Behavioral Nutrition and Physical Activity, 6, 38.

Loewen, R. \& Pliner, P. (1999). Effects of prior exposure to palatable and unpalatable novel foods on children's willingness to taste other novel foods. Appetite, 32, 351-366.

Lowe, C.F. \& Horne, P.J. (2009). Food Dudes: Increasing children's fruit and vegetable consumption. Cases in Public Health Communication \& Marketing, 3,161-185.

Lowe, C.F., Horne, P.J., Tapper, K., Bowdery, M. \& Egerton, C. (2004). Effects of a peer modelling and rewards-based intervention to increase fruit and vegetable consumption in children. European Journal of Clinical Nutrition, 58, 510-522.

Macfarlane, A. (1975). Olfaction in the development of social preferences in the human neonate. Ciba Foundation Symposium, 33, 103-117. 
Maier, A., Chabanet, C., Schaal, B., Leathwood, P., \& Issanchou, S. (2007). Food-related sensory experience from birth through weaning: Contrasted patterns in two nearby European regions. Appetite, 49, 429-40.

Monahan, J.L., Murphy, S.T. \& Zajonc, R.B. (2000). Subliminal mere exposure: Specific, general, and diffuse effects. Psychological Science, 11, 462-466.

Morris, J.L. \& Zidenberg-Cherr, S. (2002). Garden-enhanced nutrition curriculum improves fourthgrade schoolchildren's knowledge of nutrition and preferences for some vegetables. Journal of the American Dietetic Association, 102, 91-93.

Mustonen, S., Rantanen, R. \& Tuorila, H. (2009). Effect of sensory education on school children's food perception: A 2-year follow-up study. Food Quality \& Preference, 20, 230-240.

Mustonen, S. \& Tuorila, H. (2010). Sensory education decreases food neophobia score and encourages trying unfamiliar foods in 8-12-year-old children. Food Quality \& Preference, 21, 353-360.

NHS Information Centre (2009). Statistics on obesity, physical activity and diet: England, February 2009. The Health \& Social Care Information Centre, http://www.ic.nhs.uk

Nicklas, T., Webber, L. \& Berenson, G. (1991). Studies of consistency of dietary intake during the first four years of life in a prospective analysis: Bogalusa heart study. Journal of American College of Nutrition, 10, 234-241.

Nicklaus, S., Boggio, V., Chabanet, C. \& Issanchou, S. (2004). A prospective study of food preferences in childhood. Food Quality \& Preference, 15, 805-818.

Nicklaus, S., Boggio, V., Chabanet, C, \& Issanchou, S. (2005). A prospective study of food variety seeking in childhood, adolescence and early adult life. Appetite, 44, 289-297.

Perlman, D. \& Oskamp, S. (1971). The effects of picture content and exposure frequency on evaluations of negroes and whites. Journal of Experimental Social Psychology, 7, 503-514.

Pliner, P. (1982). The effects of mere exposure on liking for edible substances. Appetite, 3, 283-290. 
Pliner, P. (1994). Development of measures of food neophobia in children. Appetite, 23,147-163.

Pliner, P., Polivy, J., Herman, C.P. \& Zakalusny, I. (1980). Short-term intake of overweight individuals and normal weight dieters and non-dieters with and without choice among a variety of foods. Appetite, 1, 203-213.

Raudenbush, B. \& Frank, R.A. (1999). Assessing food neophobia: The role of stimulus familiarity. Appetite 32, 261-271.

Reverdy, C., Chesnel, F., Schlich, P., Köster, E.P. \& Lange, C. (2009). Effect of sensory education on willingness to taste novel food in children. Appetite, 51, 156-165.

Rolls, B.J. (1986). Sensory-specific satiety. Nutrition Reviews, 44, 93-101.

Rolls, B.J. \& Hetherington, M. (1989). The role of variety in eating and body weight regulation. In R. Shepherd (Ed.), Handbook of the psychophysiology of human eating (pp. 57-84).Chichester: Wiley.

Rolls, B., Rolls, E., Rowe, E., \& Sweeney, K. (1981). Sensory specific satiety in man. Physiology \& Behavior, 27, 137-142.

Rozin, P. (1976). The selection of foods by rats, humans and other animals. In J.S. Rosenblatt (Ed.), Advances in the study of behaviour (6 $6^{\text {th }}$ edition). New York: Academic Press.

Rozin, P. \& Schiller, D. (1980). The nature and acquisition of a preference for chili pepper in humans. Motivation \& Emotion, 4, 77-101.

Skinner, J.D., Carruth, B.R., Bounds, W., Ziegler, P. \& Reidy, K. (2002a). Do food-related experiences in the first 2 years of life predict dietary variety in school-aged children? Journal of Nutrition Education and Behavior, 34, 310-315.

Skinner, J.D., Carruth, B., Wendy, B. \& Ziegler, P. (2002b). Children's food preferences: A longitudinal analysis. Journal of the American Dietetic Association, 102, 1638-1647.

Steiner, J.E. (1979). Human facial expressions in response to taste and smell stimulation. Advances in Child Development \& Behaviour, 13, 257-295. 
Story, S. \& French, S. (2004). Food advertising and marketing directed at children and adolescents in the US. International Journal of Behavioral Nutrition and Physical Activity, 1, 1-3.

Sullivan, S.A. \& Birch, L.L. (1990). Pass the sugar, pass the salt: Experience dictates preference. Developmental Psychology, 26, 546-551.

Tuorila, H., Meiselman, H.L., Bell, R., Cardello, A.V. \& Johnson, W. (1994). Role of sensory and cognitive information in the enhancement of certainty and liking for novel and familiar foods. Appetite, 23, 231-246.

Tuorila, H. \& Mustonen, S. (2010). Reluctant trying of an unfamiliar food induces negative affection for the food. Appetite, 43, 418-421.

Visalberghi, E. \& Addessi, E. (2000). Seeing group members eating a familiar food enhances the acceptance of novel foods in capuchin monkeys. Animal Behaviour, 60, 69-76.

Wardle, J., Carnell, S. \& Cooke, L. (2005). Parental control over feeding and children's fruit and vegetable intake: How are they related? Journal of the American Dietetic Association, 105, 227-232.

Wardle, J. \& Cooke, L. (2008). Genetic and environmental determinants of children's food preferences. British Journal of Nutrition, 99, (Suppl. 1), S15-S21.

Wardle, J., Cooke, L., Gibson, E.L., Sapochnik, M., Sheiham, A. \& Lawson, M. (2003a). Increasing children's acceptance of vegetables: A randomized trial of parent-led exposure. Appetite, 40, 155162.

Wardle, J., Herrera, M.L., Cooke, L. \& Gibson, E.L. (2003b). Modifying children's food preferences: The effects of exposure and reward on acceptance of an unfamiliar vegetable. European Journal of Clinical Nutrition, 57, 341-348.

Williams, K.E., Paul, C., Pizzo, B. \& Riegel, K. (2008). Practice does make perfect: A longitudinal look at repeated taste exposure. Appetite, 51, 739-742. 
Wind, M., de Bourdeaudhuij, I., te Velde S.J., Sandvik, C., Due, P., Klepp, K.I. \& Brug, J. (2006). Correlates of fruit and vegetable consumption among 11-year-old Belgian-Flemish and Dutch schoolchildren. Journal of Nutrition Education \& Behavior, 38, 211-221.

Wright, P. (1991). Development of food choice during infancy. Proceedings of the Nutrition Society, 50, $107-113$.

Zajonc, R. (1968). Attitudinal effects of mere exposure. Journal of Personality \& Social Psychology, 9 , 1-27. 


\section{Figure Captions}

Fig. 1. Total looking times in milliseconds (ms) towards exposed and non-exposed fruit and vegetables $(* * \mathrm{p}<0.005 ; * \mathrm{p}<0.05)$ that were initially liked, disliked or unfamiliar to the child (Heath, HoustonPrice \& Kennedy, 2010). 
Figure 1

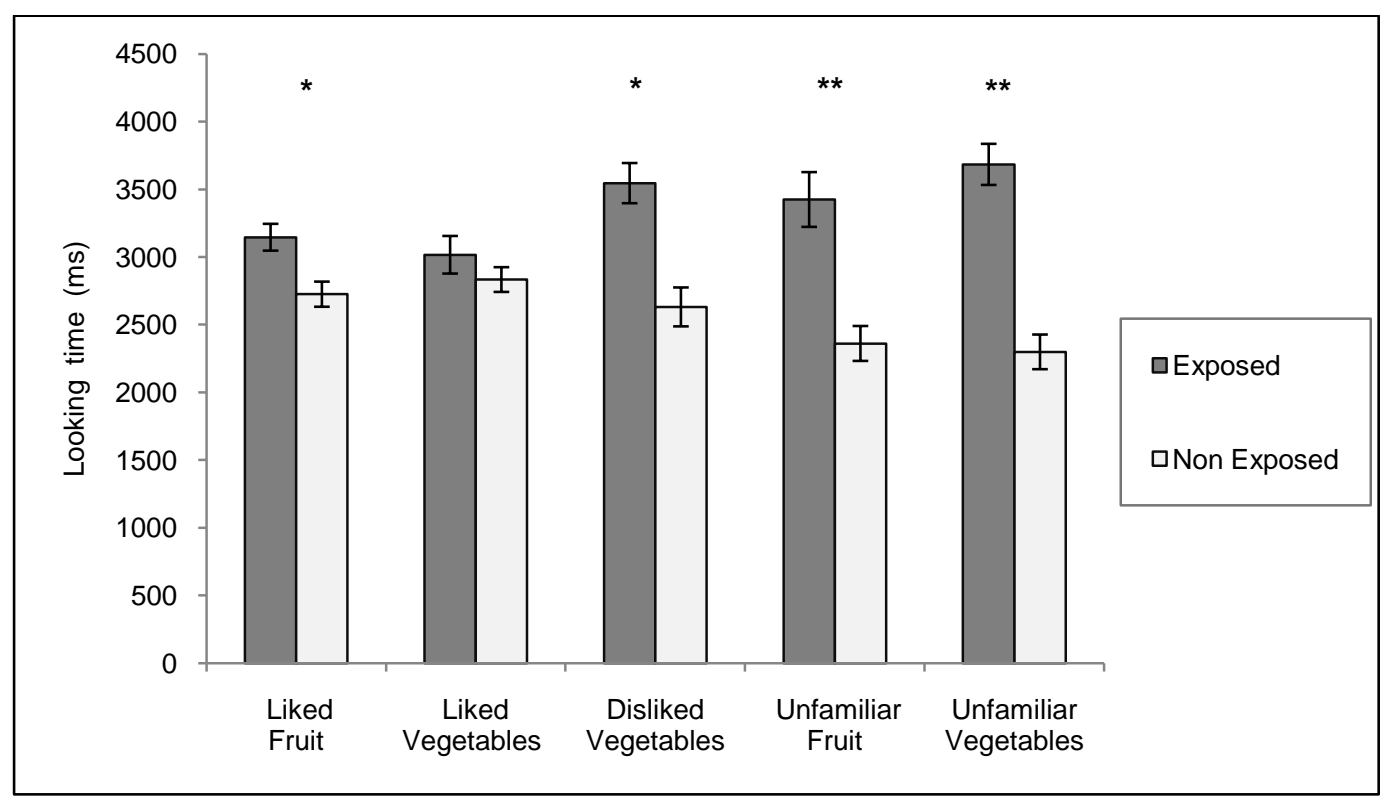

